Jermyn, Deborah, Holmes, Susan (Eds.), Women, Celebrity and Cultures of Ageing: Freeze Frame, 2015, Palgrave Macmillan reproduced with permission of Palgrave Macmillan. This extract is taken from the author's original manuscript and has not been edited. The definitive, published, version of record is available here: http:/www.palgrave.com/gb/book/9781137495112 


\title{
From the Woman Who 'Had It All' to the Tragic, Ageing Spinster: The Shifting Star Persona of Jennifer Aniston
}

\author{
Susan Berridge
}

In a montage episode of Friends (NBC, 1994-2004), 'The One Where They All Turn 30' (7.14), Rachel (Jennifer Aniston) sits down to a birthday breakfast with her friends and 24-year-old boyfriend, surrounded by colourful balloons. Dressed in a plain white T-shirt and pyjama bottoms, with shoulder-length bobbed hair and wearing a child's birthday crown, her youthful girlishness is highlighted. Yet, while the episode underlines Rachel's youth, it simultaneously suggests that she is at an inappropriate life stage in relation to her age. Rachel's narrative in the episode revolves around her anxieties about getting older without having achieved any of her self-imposed life goals goals that include meeting a man, getting married and having children. Reinforcing the idea of Rachel as in a state of arrested development, she is currently living in Joey (Matt LeBlanc) and Chandler's (Matthew Perry) former apartment, a space that connotes immaturity in the series more widely - connected as it is with bachelor and often childish lifestyles. In keeping with the generic conventions of the sitcom, Rachel's response to turning 30 is portrayed as a comedic overreaction. Yet, the narrative ultimately culminates with Rachel splitting up with her boyfriend to concentrate instead on her realising her long-term aims. In doing so, the episode clearly articulates some of the central tenets of postfeminist discourses of ageing and 'time crisis', which measure success through the attainment of particular life goals such as marriage and motherhood (Negra, 2009).

What is striking about the episode is the disjuncture between Rachel's life and Aniston's life at the time that it aired. The episode was broadcast for the first time in early 2001, at a point when Aniston was 31 and newly married to A-List film star Brad Pitt. Thus, at the same time that Rachel fretted over her 'temporal failure', Aniston was arguably the poster girl for 'having it all' - the envied haircut, the highly successful television career, the youthful girl-next-door good looks, the dream husband, and with it, implicitly, the prospect of 'starting a family'. Significantly, this was reversed just a few years later. Rachel ended up by the finale of Friends, broadcast in 2004, with her 'happy ending', having reunited with the father of her daughter and long-time on-off love interest Ross. In contrast, Aniston was facing an imminent separation from Pitt, amidst rumours of his affair with Angelina Jolie. Accordingly, her star image suddenly and dramatically shifted from the girl to aspire to, to the doomed and ageing singleton, all while she was still in her (early) 30s.

Currently, in the landscape of female celebrity, Aniston constitutes one of the most important discursive sites for anxieties around gender, age and chronological propriety. It is difficult to think of equivalent female celebrities 
who have remained unwed and childfree into their 40s and been such permanent fixtures on the front covers of celebrity gossip and women's magazines as Aniston. As Diane Negra notes, 'In postfeminist culture the single woman stands as the most conspicuously time-beset example of contemporary femininity, her singlehood encoded as a particularly temporal failure and a drifting off course from the normative stages of the female lifecycle' (2009: 61). Despite now being engaged to be married to Justin Theroux, at the time of writing in late 2014, Aniston continues to be positioned as a high-profile exemplar of precisely this 'temporal failure' outlined by Negra. Examining interviews conducted with the star in women's magazines as well as coverage of Aniston in celebrity gossip and entertainment magazines from both the UK and US, and focusing predominantly on the period following her split with Pitt in 2005, this chapter will explore Aniston's shifting star persona in more depth, situating this discussion in relation to postfeminist discourses of ageing. I argue that Aniston can be seen as emblematic of how the ageing, unwed and childfree woman has been treated by popular culture at a particular moment in time at the start of the new millennium and thus, offers a crucial case study to explore the powerful and punishing ways in which gender intersects with critical discourses of ageing.

\section{Ageing, Celebrity Studies and feminism}

$\mathrm{Su}$ Holmes and Negra foreground the gendered differences in the media treatment of male and female celebrities, particularly when they 'fall from grace', arguing that there is a heavy emphasis on policing inappropriate or 'out of bounds' behaviour in women in the current media climate (2011: 2). Significantly, this idea of 'out of bounds' behaviour is inextricably linked to gendered notions of temporal propriety, and yet in both feminist and Celebrity Studies, age has been less carefully attended to than other forms of identity. The relative lack of scholarship that considers the relationship between ageing, gender and stardom is all the more surprising given what is at stake, particularly for 'older' female celebrities who typically lose visibility as they age.

As Holmes and Negra note, Celebrity Studies and feminist studies have not traditionally been seen as 'natural bedfellows', partly due to the way in which celebrity culture often focuses on the intense scrutiny and judgement of the physical appearance of female celebrities (2011: 14). Moreover, contemporary feminist studies of stardom have tended to focus on young female stars, reflecting the way in which celebrity culture itself privileges youth. Celebrity culture and Western culture more widely are marked by a fear of ageing, which is typically constructed as a kind of 'trauma', 'linked to a prevailing but increasingly, if problematically, contested understanding of age primarily in terms of decline and disintegration rather than accumulation and growth' (Wearing, 2007: 280).

Yvonne Tasker and Negra suggest that 'the ambivalence about aging that strongly characterizes such fictions is also extended to feminism itself. As postfeminism has raised the premium on youthfulness, it has installed an image of feminism as “old” (and by extension moribund)' (2007: 11). This is not necessarily a new phenomenon. Kathleen 
Woodward argues that 'ageism is entrenched within feminism itself', using the 1980s example of lesbian feminists feeling alienated by the women's movement due to their older age (1999: xi). That said, the notion or construction of second-wave feminism as outdated and redundant has certainly become increasingly pronounced in more recent years with the rise of postfeminist culture.

Notably, there is no common consensus over what the term 'postfeminism' entails. It can be interpreted in vastly different ways depending on a particular scholar's political beliefs, with some criticising the term for implying that the goals of feminism have already been achieved and others viewing the term more positively as a useful descriptor for recent changes in the media representation of women (Gill, 2007). Importantly, generational difference becomes central to these debates. There may be no common agreement on what postfeminism entails, but it is nevertheless differentiated from second-wave, or 'older', feminism. Charlotte Brunsdon explains that second-wave feminism often becomes the other of postfeminist women, who falsely demonise this earlier, older generation for repressing all sense of difference between women and for being excessively hostile (2006: 43).

In her analysis of screen representations of 'older' women, Sadie Wearing questions connections between the "“aging” of feminism and culturally authoritative narratives and anxieties over age more generally' (2007: 280). Wearing's chapter is one of a number of more recent feminist studies examining the links between gender and age in relation to older female celebrities (see also Tally, 2008; Morley, 2011; Jermyn, 2011, 2012a). This growing interest in ageing is further evidenced by the 2012 special issue of Celebrity Studies, introduced by Deborah Jermyn and entitled 'Back in the Spotlight: Female Celebrity and Ageing' (2012b). Many of the women discussed in this scholarship - including stars such as Diane Keaton and Meryl Streep - are notably older than Aniston by a few decades, pointing to the importance of recognising the subjectivity of ageing and what constitutes an 'older woman' (Jermyn, 2012b). Age is not a fixed category but is instead constantly shifting, particularly in recent years as postfeminist culture has given license, and indeed made it aspirational, for women to be youthful and girly at an older age (Jermyn, 2012b: 1). And yet, despite the fact that Aniston is younger than many of the female stars discussed in this emerging academic criticism, it remains striking that media coverage of the star still repeatedly draws attention to her age and holds her age-accountable in ways that equivalent male stars are not. Thus, Aniston is a vital example to use to develop this recent scholarship further. This chapter will pay particular attention to the way in which extratextual discourses of the star intersect with (gendered) discourses of ageing.

\section{Acting your age, looking your shoe size}

Postfeminist media culture is characterised by an intense preoccupation with the body, particularly the female body, and underpinned by themes of self-surveillance, monitoring and discipline (Gill, 2007: 6). This is no more evident than in the celebrity gossip industry, which focuses on the scrutiny and judgement of the female celebrity, examining 
these stars in order to discern how effectively they have managed to evade the physical signs of ageing and thus conform to normative postfeminist constructions of youthful beauty (Fairclough, 2012: 90). This scrutiny is motivated by a fetishisation of youth where ageing is 'imagined less as an inevitable, natural process than as a moral failing' (Wearing, 2007: 287). In postfeminist culture, the onus for maintaining a youthful appearance lies firmly with the individual female, with extended girlhood offered as a fantasy for everyone regardless of their age (Tasker and Negra, 2007: 18).

Reflecting this contemporary obsession with youth, articles on Aniston commonly begin by mentioning her age and include discussions of her appearance as is typical with female celebrities of all ages, most often praising her youthful looks and positioning her as someone to aspire to. An interview with the star in Elle notes that, 'In flip-flops, snug Generra jeans, and a black T-shirt stamped with a skull sticking a red tongue out at the world, Aniston, 36, doesn't look old enough to drink. She has smooth, tawny skin, and thick, caramel-color hair pin-streaked with blond frames her small face' (Milea, 2005). While this article was written in 2005, the celebration of Aniston's youthful appearance persists a decade on. A relatively recent interview with Aniston and Paul Rudd in $G Q$ starts by noting that 'both look astonishingly the same as they did two decades ago' (Martin, 2012). GQ featured another article on Aniston a year later, heralding her as 'Woman of the Week' and noting that Aniston seems 'to be living in some alternate universe where time stands still', illustrating the piece with three images of Aniston at 36, 40 and 43 years old (Clark, 2013).

This aspirational praise of Aniston's youthful appearance is often coupled with criticism of how much she spends to achieve this look, pointing to a key paradox at the heart of celebrity and postfeminist culture. Kirsty Fairclough (2012) highlights the precarious balance that must be achieved by female celebrities between maintaining youthful beauty and not appearing to try too hard for fear of seeming desperate. Fairclough identifies the 'desperate' as a category constructed by the gossip industry and applied to celebrities over 40 who are 'configured as desperate to remain youthful in order to suspend time and reclaim their once glittering careers and images, but are often constructed as failing at both' (2012: 97). With this failure, these celebrities tend to be maligned in the popular press, their attempts at maintaining a youthful appearance via cosmetic surgical procedures taking precedence over their actual work (ibid.). Similarly, Wearing argues that, 'A very familiar double standard seems to be in operation in a culture that finds the signs of age in female bodies grotesque, laughable, and fearful (and makes a spectacle out of them) but equally mistrusts the efforts to efface those signs' (2007: 290).

While Aniston is typically seen to be ageing well and in 'acceptable ways', she nonetheless faces denigration for not being fully transparent in her efforts to evade the ageing process (Fairclough, 2012: 98). In 2014, InTouch ran a piece which noted incredulously the price Aniston pays to maintain her youthful demeanour ('Say What?!: Jennifer 
Aniston Spends \$8K a Month on Beauty Treatments to Keep Justin Theroux'), adding that she has 'been secretly spending thousands of dollars to stay looking young' and promising to reveal her secrets (Cooper, 2014). The use of the word 'secretly' here evokes the sense of mistrust and deceit around the efforts used to remain looking young. More significantly, the article positions Aniston as someone who must stave off the signs of ageing in order to keep her man. This reflects the way in which postfeminist culture evokes anxieties around ageing, suggesting that not maintaining a youthful appearance will result in romantic rejection and drawing heavily upon discourses of personal responsibility. Here, the onus for defying ageing is firmly placed on Aniston, containing any broader discussions of gendered inequalities.

This example speaks to one of the central contradictions in the way that discourses of ageing are evoked in media coverage of Aniston's star persona, particularly following her separation from Pitt. Aniston is widely praised for maintaining the physical signs of youth - with articles mentioning her smooth, unblemished skin, shiny hair and taut body - but at the same time, she is also frequently positioned in the popular press as a high-profile exemplar of the dangers of not achieving particular gendered life goals by a certain age. While postfeminism may offer fantasies of 'age-transcendence' in terms of looking young, there are simultaneously strict limits imposed on temporal propriety and, specifically, on matching women's age with the appropriate (and highly gendered) life stage (Negra, 2009: 14). As Negra identifies, 'one of the signature attributes of postfeminist culture is its ability to define various female life stages within the parameters of "time panic", as evidenced in the aforementioned Friends episode (Negra, 2009: 47). Postfeminist culture suggests that the solution to this time crisis lies in becoming more feminine, by finding a (heteronormative) romantic partner and having a baby, thus 'forcefully renewing conservative social ideologies centering on the necessity of marriage for young woman and the glorification of pregnancy' (Negra, 2009: 47). Although postfeminist culture celebrates the notion of choice and empowerment for women, these choices are deeply constrained and limited.

While Aniston has not been subject to quite the same degree of public scrutiny, in relation to whether she has or has not had cosmetic surgery, as other 'older' female stars, she is nevertheless often on the receiving end of a different kind of 'biological' scrutiny, with near constant speculation over her (in)fertility. This emphasis on Aniston's (in)fertility highlights further the gendered nature of ageing celebrity discourses, drawing attention to the way that female stars are expected to account for their age and equivalent life stage in ways that male stars need not. Even before Aniston separated from Pitt, there was frequent media speculation about whether she was pregnant yet and, if not, why not (cf. the covers of numerous UsWeekly magazines from the early 2000s which reveal a near constant obsession with Aniston's fertility, asking of Pitt and Aniston in 2002 'will they ever have babies?' and stressing the couple's baby struggles two years later as a reason for their split). Similarly, a 2002 article in Time Europe, albeit 
mocking the media obsession with Aniston's fertility, nonetheless began by stating that Aniston and Pitt were not yet trying for a baby (Cagle and Won Tesoriero, 2002).

The media's obsession with Aniston's fertility has intensified as she has moved into her 40s. For example, a recent issue of UsWeekly focuses on new rumours about whether Aniston is pregnant with Theroux's child (Lee, 2014). Reflecting upon the sexist and ageist logics that underpin contemporary celebrity culture, Holmes and Negra maintain that, 'When female celebrity life choices and personal circumstances do not fit (or no longer fit) within a "family values" script, one option is for them to be cast in the mode of another postfeminist archetype, the "sad singleton"' (2011: 8). They directly cite Aniston as an example of such a celebrity who is treated with dismay. Where marriage and motherhood are equated with full womanhood, postfeminist culture perpetuates the notion that unwed, childless women's lives are somehow lacking and/or not yet underway.

In media coverage of the star following her separation from Pitt, she is overwhelmingly cast as a victim, someone to be pitied. While it is widely accepted that Pitt instigated their split, in discussions of Aniston's love life prior to her engagement to Theroux, there is little sense that singleness and/or childlessness (childfree-ness) might be an active or desirable choice on her part. Interviews directly following her separation frequently adopt a sentimental and mournful tone. Exemplifying this, her famous 2005 interview with Vanity Fair - the first interview she gave following the break up - includes the line: 'a testament to both [Pitt's] passion for architecture and the couple's hopeful vision of their shared future, the beautiful old house awaited only a baby in a bassinet to complete a pictureperfect existence ... Instead of the joyful announcement many had anticipated from the Pitts, there was only silence"'(Bennetts, 2005), again echoing the notion of normative, gendered life stages.

Gossip magazines similarly position Aniston as someone to be pitied. UsWeekly covers in the years immediately following her separation have repeatedly emphasised Aniston's inability to find a new romantic partner, almost always positioning her as a victim in each new relationship: an issue from 16 October 2006 talks about 'why Vince left Jen', referring to her relatively brief relationship with fellow actor Vince Vaughn, while 25 December 2006's issue announced that 'Jen Suffers Another Humiliating Split'. An issue dated 30 July 2007 aligned Aniston with Jessica Simpson and Cameron Diaz, asking 'Why Can’t They Find Love: Beautiful, Rich and Alone', while later issues focus on Angelina Jolie ‘torturing' and spreading 'nasty rumors' about Aniston (19 November 2008 and 23 November 2009, respectively). The notion of Aniston as victim in her own love life has decreased slightly since her engagement to Theroux, yet even now, gossip magazines frequently suggest that their relationship might be troubled. For example, the cover of 13 December 2013's issue of Grazia announced: 'Jen and Justin: Split Rumours Hot Up' (Amer, 2013). 
Paradoxically, while Aniston is cast as the victim in these discussions suggesting a lack of agency and control, at the same time, this is accompanied by suggestions that it was her career-minded attitude that cost her her marriage to Pitt and any subsequent children. The implication here is that Aniston mismanaged her timings. By allowing herself to be distracted from the imperative to start a family at the sanctioned point in the timetable of normative femininity, she is now seen to be paying the price years later. At times, Aniston has attempted to highlight the inherent sexism underpinning the notion that she was to blame for her break up, arguing in Elle that 'a man divorcing would never be accused of choosing career over children' (Hahn, 2009). But almost in the same breath, she then reaffirms heteronormative life goals such as motherhood, stating: 'I've never in my life said I didn't want to have children. I did and I do and I will! ... I've always wanted to have children, and I would never give up that experience for a career. I want to have it all' (Hahn, 2009).

Notably, victimhood is the antithesis of postfeminism, as it exposes the failure to take advantage of possibilities of empowerment - of 'having it all' - supposedly available to women in the contemporary era, regardless of their age. Aniston emphatically rejects the term, arguing in Vanity Fair that 'to live in a victim place is pointing a finger at someone else, as if you have no control' (Bennetts, 2005). Instead, she commonly positions herself as someone to be empathised with, rather than sympathised with. This is clearly evidenced in a 2009 interview in Elle in which she argues that, 'I support women, men, anybody who is in a place that's not their strongest and who is ready to push forward. So if I'm the emblem for this is what it looks like to be the lonely girl getting on with her life, so be it ... Don't we all have days when we feel lonely...?' (Hahn, 2009, original emphasis). Her use of the term 'we' here works to align her with any person who has experienced heartache, thus underlining the universality of her situation. Aniston's star image more widely is predicated on the notion of her being accessible, and this accessibility notably hinges on connotations of authenticity and youthfulness. Aniston positions herself as the inherently low-maintenance, girl next door, reinforced by her preference for simple (albeit expensive, designer) outfits and 'natural', low-key (yet highly groomed) styling when at red carpet events.

Paradoxically, further emphasising her accessibility and ordinariness, her similarity to Rachel Green in Friends is also often emphasised in interviews, thus capitalising on the domestic, intimate nature of the television medium and the intense forms of identification it can promote (Ellis, 1982). Her Vanity Fair interview includes the line “'I haven't been feeling emotional lately, really I haven't," she wails, fluttering her hands like Rachel Green in distress' (Bennetts, 2005). Parallels between Aniston and Rachel persist to the current day. For example, when Aniston sported a shorter haircut in 2013, UsWeekly ran a nostalgic article about 'The Rachel', her iconic layered haircut that she debuted in Friends back in 1994 (Eggenberger, 2013). As these analogies to Rachel evoke a period when Aniston was in her mid-20s to early 30s, they arguably add to the sense of chronological failure underpinning 
contemporary discussions of the star. With the closure of Friends in 2004, Rachel remains perpetually 35, with a daughter and partner, in stark contrast to the route that Aniston's life has taken since. If Friends encouraged viewers to root for Rachel's eventual romantic union with on-off love interest Ross (David Schwimmer) over the series' ten seasons, then it is interesting to consider whether this long-term investment in Rachel's love life has been transposed onto Aniston following the series' end.

Significantly, the shift in Aniston's star persona from the girl who 'had it all' to the ageing, pitiful singleton coincided with the end of her hugely popular portrayal of Rachel and a move from television towards film roles, many of which draw thematic parallels to her personal life. Arguably, the success of Aniston's films pales in significance to extratextual discussions of her private life, a pattern that is true of many female stars (Geraghty, 2000). Articles that purport to promote one of her upcoming films frequently detour into discussions of her previous relationship with Pitt, her rivalry with Jolie, her love life and/or her (in)fertility. Yet Aniston's private and professional lives cannot be read as entirely separate. Richard Dyer notes that traditionally 'the roles and/or the performance of a star in a film were taken as revealing the personality of the star' (1979: 22 cited in Jermyn, 2006: 73).

Arguably, Aniston is most well-known for her roles in romantic comedies, which several scholars have identified as a particularly conducive genre for representing 'older' women (Tally, 2008; Wearing, 2007; Jermyn, 2011, 2012a; Morley, 2011). Negra argues that temporal anxiety is a common feature of contemporary romantic comedies, noting that in these films, management of the ageing process and, specifically, achieving the 'appropriate' postfeminist life goals - falling in love, getting married, having children - are positioned as key to personal fulfilment (Negra, 2009: 53). Many of Negra's examples prominently feature Aniston as the central love interest, including Along Came Polly (Hamburg, 2004) and Bruce Almighty (Shadyac, 2003), as well as Picture Perfect (Gordon Caron, 1997).

Picture Perfect offers an interesting example of how Aniston's fictional roles embody the same fears around temporal failure as the extratextual discourses surrounding her personal life. Even though this was her first starring film role, released in 1997 when Aniston was 28 years old, and before she met Pitt, it still emphasises temporal anxieties. Aniston plays Kate, an independent, single woman working at a successful advertising firm. While she is vocal about her enjoyment at being single and self-sufficient, she finds herself struggling to progress at work due to the fact that she has not yet attained any of the key markers of maturity - her own car, house, a husband, children while her mother (played by Olympia Dukakis) constantly pressures her to get married and give her a grandchild.

In Aniston's later roles, particularly her roles following her split from Pitt, this sense of urgency around achieving key life goals 'in time' increases. In 2006, she starred in The Break-Up (Reed, 2006) with her real-lifeboyfriend-at-the-time, Vince Vaughn, followed by He's Just Not That Into You (Kwapis, 2009) in which she plays a 
woman longing for her reluctant boyfriend to propose; The Switch (Gordon and Speck, 2010, co-produced by Aniston), in which she plays an unmarried 40-year-old desperate for a baby; and We're the Millers (Thurber, 2013), which features Aniston as an ageing, single stripper who becomes a surrogate mother to two teenagers. Interviews with the star often identify the parallels between her personal life and professional roles. For example, 'she deserves better than getting-the-guy flicks. Aniston can tell you all about getting the guy. She deserved better than that, too.' (Milea, 2005). Aniston herself did the same in a humorous speech delivered at the 2009 Women in Film Awards where she traced connections between her life offscreen and her film titles, ending by joking, 'If any of you have a project called "Everlasting Love with an Adult Stable Male", just go to my table'.

If these roles all feature Aniston playing women who are longing for romantic commitment and children as they grow older, the flipside to this are her roles as a predatory, older single woman in the films Horrible Bosses (Gordon, 2011) and Horrible Bosses 2 (Anders, 2014) as well as in her 2008 guest role in the television sitcom 30 Rock (NBC, 2006-2013) in which she plays a wild, unhinged party 'girl', made an object of disgust because she is now too old for such an irresponsible, chaotic lifestyle (3.03 'The One with the Cast of Night Court'). In these latter roles she is less interested in commitment than in, respectively, casual sex and desperately clinging to the lifestyle of her youth. What all these roles have in common, regardless of whether Aniston's characters are portrayed as longing for romantic monogamy or simply looking for no-strings-attached sex, is an emphasis on chronological decorum (or lack of it). The humour in her roles in Horrible Bosses and its sequel as well as in 30 Rock partly derives from the age-inappropriateness of her behaviour, thereby reaffirming the normativity of postfeminist life stages.

As Rebecca Williams notes in her insightful analysis of Drew Barrymore's shifting star persona, generic expectation can undermine the idea of the star as author of their own image (2007: 117). In Aniston's case, while she frequently and emphatically rejects the construction of herself as a romantic 'victim' and, more recently, has been outspoken about how much she enjoys being in her 40s, her ability to construct her star image on these terms could be seen to be restricted by the kinds of roles she plays. However, I hesitate to suggest that Aniston has no agency in the way that her persona has been constructed. For example, it is difficult to know with certainty whether these are the only roles she is offered, or conversely, whether she actively chooses to play these kinds of parts. Arguably, her 'unlucky in love' image reinforces her commercial interests, illustrated by the close parallels between her film roles and star persona and her enduring presence on the front covers of women's and gossip magazines, many of which have close ties with the film industry and its promotional needs. It is not as simple, then, as the press constructing an image of Aniston as someone to be pitied and Aniston then challenging this reading. Although Aniston rejects the victim role, at the same time, she often reaffirms the hegemonic equation of personal fulfilment with heteronormative marriage and motherhood. 
However, even if Aniston does play a part in the way that her star image is constructed, what does this say about the kinds of choices offered to single women of a particular age in Hollywood? Aniston may have remained firmly in the public sphere following her divorce, but this has been accompanied by near constant judgement of her appearance and life choices, particularly her lack of children. As Negra asserts, 'postfeminism might be seen as particularly punishing in its relation to single women, having raised their cultural profile though without any corresponding enlargement of their status/options' (2009: 10).

The simultaneous celebration/repudiation of the older, single woman reflected in Aniston's film roles and extratextual discourses surrounding the star is emblematic of a postfeminist sensibility which both fetishises youth and offers promises of age-transcendence, while at the same time measuring success in relation to strict temporal management. Aniston's ‘temporal failure' is variously positioned in gossip and women's magazines as beyond her control and as her responsibility, highlighting the contradictions and complexities underpinning postfeminist culture, which both celebrates women's empowerment and the notion of choice while at the same time cautioning against female autonomy by implying that independence may lead to emotional isolation (Tasker and Negra, 2007). Just as postfeminism embraces the notion of choice, at the same time, it individualises these choices, suggesting that the responsibility for 'having it all' lies firmly with the individual woman. This implication, in turn, obscures any broader discussions of gendered inequalities (Gill, 2007: 12). It is worth noting that there is no equivalent emphasis on ageing and 'time crisis' circulating around male celebrities; George Clooney's unmarried and childless status up until 2014 , for example, was configured in the media not as failure but as evidence of his still being engagingly footloose, even into his $50 \mathrm{~s}$.

It is important to recognise that Aniston's star image is open to polysemic interpretations. Hers is also a dynamic persona that is subject to change, particularly at the present moment in light of her current engagement. More detailed research needs to be undertaken into how audiences engage with the extratextual discourses surrounding the star. Yet, nevertheless, through looking at a range of women's, gossip and entertainment magazine coverage of the star from both the UK and US, important patterns begin to emerge. These patterns point to the way in which female celebrities have become a key site upon which anxieties about ageing and femininity, and particularly in Aniston's case marriage and motherhood, are played out (Fairclough, 2012: 90-91). Looking at the extratextual discourses surrounding Aniston reveals that postfeminist culture intersects powerfully with representations of singleness in a way that limits the kinds of stories being told about single women (Taylor, 2012). For all the rhetoric of 'choice' that underpins postfeminism, remaining unwed and childless/childfree beyond a certain age does not appear to be one of them.

\section{References}


Amer, C. (2013) 'Jen and Justin: Split Rumours Hot Up', 13 December, Grazia online, available at http://www.graziadaily.co.uk/LatestIssue/in-this-weeks-issue--jen---justin-splitrumours-hot-up-plus-the-latest-on-nigellas-court-drama [accessed October 29 2014].

Anon (2002-2014) 'Jennifer Aniston's UsWeekly Covers', available at http://www.usmagazine.com/celebrity-news/pictures/jennifer-anistons-us-weeklycovers-201382/28166 [accessed 21 October 2014].

Bennetts, L. (2005) 'The Unsinkable Jennifer Aniston', September, Vanity Fair online, available at http://www.vanityfair.com/culture/features/2005/09/aniston200509 [accessed 6 May 2013].

Brunsdon, C. (2006) 'The Feminist in the Kitchen: Martha, Martha and Nigella', in J. Hollows and R. Moseley (eds) Feminism in Popular Culture (Oxford and New York: Berg), pp. 41-56.

Cagle, J. and Won Tesoriero, H. (2002) 'Oh-So-Sunny in Friends, Aniston Gets Serious in Her New Film', 18 November, Time Europe, 160(21), p. 66.

Clark, D. (2013) 'Woman of the Week: Jennifer Aniston', 15 February, GQ online, available at http://www.gq.com/blogs/the-feed/2013/02/woman-of-the-week-jennifer-aniston.html [accessed 20 October 2014]

Cooper, D. (2014) 'Say What?! Jennifer Aniston Spends \$8K a Month on Beauty Treatments to Keep Justin Theroux', 31 March, InTouch online, available at http://www.intouchweekly.com/posts/jennifer-aniston-spends-8k-a-month-on-beautytreatments-to-keep-justin-theroux-36656 [accessed 20 October 2014].

Dyer, R. (1979) Stars (London: BFI).

Eggenberger, N. (2013) 'Jennifer Aniston Would Rather Shave Her Head Than Have "The Rachel” Cut Again', 13 August, UsWeekly online, available at http://www.usmagazine.com/celebrity-beauty/news/jennifer-aniston-would-rathershave-her-head-than-have-the-rachel-cut-again-2013138 [accessed 10 December 2014].

Ellis, J. (1982) Visible Fictions: Cinema, Television, Video (London: Routledge).

Fairclough, K. (2012) 'Nothing Less Than Perfect: Female Celebrity, Ageing and Hyper-scrutiny in the Gossip Industry'. Celebrity Studies, 3(1), pp. 90-103.

Geraghty, C. (2000) 'Re-examining Stardom: Questions of Texts, Bodies and Performance', in S. Redmond and S. Holmes (eds) Stardom and Celebrity: A Reader (London: Sage), pp. 98-110. 
Gill, R. (2007) 'Postfeminist Media Culture: Elements of a Sensibility', European Journal of Cultural Studies, 10(2), pp. 147-166.

Hahn, K. (2009) 'Jennifer Aniston: Hollywood's Sweetheart Reveals the Calm Behind the Storm the Tabloids Have Created', 4 August, Elle (UK) online, available at http://www.elle.com/popculture/cover-shoots/jennifer-aniston-361331 [accessed 6 May 2013].

Holmes, S. and Negra, D. (2011) (eds) 'Introduction', in In the Limelight and Under the Microscope: Forms and Functions of Female Celebrity (New York and London: Continuum), pp. 1-16.

Jermyn, D. (2006) 'Bringing out the $\star$ in You': SJP, Carrie Bradshaw and the Evolution of Television Stardom', in S. Holmes and S. Redmond (eds) Framing Celebrity: New Directions in Celebrity Culture (Oxon and New York: Routledge), pp. 67-85.

Jermyn, D. (2008) 'Still Something Else Besides a Mother? Negotiating Celebrity Motherhood in Sarah Jessica Parker's Star Story', Social Semiotics, 18(2), pp. 163-176.

Jermyn, D. (2011) 'Unlikely Heroines?: "Women of a Certain Age” and Romantic Comedy', Cineaction, pp. 26-33.

Jermyn, D. (2012a) “"Glorious, Glamorous and That Old Standby, Amorous”: The Late Blossoming of Diane Keaton's Romantic Comedy Career', Celebrity Studies, 3(1), pp. 37-51.

Jermyn, D. (2012b) ““Get a Life, Ladies. Your Old One Is Not Coming Back”: Ageing, Ageism and the Lifespan of the Female Celebrity', Celebrity Studies, 3(1), pp. 1-12.

Lee, E. (2014) 'Jennifer Aniston Is Not Pregnant with Justin Theroux's Baby: Sources Debunk New Rumour', 2 May, UsWeekly online, available at http://www.usmagazine.com/celebritynews/news/jennifer-aniston-not-pregnant-with-justin-therouxs-baby-sources-say201425\#ixzz373TbBrKQ [accessed 20 October 2014].

Martin, B. (2012) 'I Love You, Wo-Man’, 14 February, GQ online, available at http://www.gq.com/entertainment/movies-and-tv/201203/jennifer-aniston-paul-ruddgq-march-2012-cover-story [accessed 6 May 2013].

Milea, H. (2005) 'The Better Girl: Jennifer Aniston Dishes on Vince, Clive and Her "Sexy Little House", 3 October, Elle (UK) online, available at http://www.elle.com/pop-culture/covershoots/the-better-girl-19474 [accessed May 6 2013].

Morley, A. (2011) 'Grotesquerie as Marker of Success in Aging Female Stars', in S. Holmes and D. Negra (eds) In the Limelight and Under the Microscope: Forms and Functions of Female Celebrity (NY and London: Continuum), pp. 103-124. 
Negra, D. (2009) What a Girl Wants? Fantasizing the Reclamation of Self in Postfeminism (Oxon and New York: Routledge).

Tally, M. (2008) 'Something's Gotta Give: Hollywood, Female Sexuality and the "Older Bird” Chick Flick', in S. Ferriss and M. Young (eds) Chick Flicks: Contemporary Women at the Movies (New York: Routledge), pp. 119-131.

Tasker, Y. and Negra, D. (2007) (eds) 'Introduction: Feminist Politics and Postfeminist Culture', in Interrogating Postfeminism: Gender and the Politics of Popular Culture (Durham, NC: Duke University Press), pp. 1-25.

Taylor, A. (2012) Single Women in Popular Culture: The Limits of Postfeminism (Hampshire and New York: Palgrave Macmillan).

Wearing, S. (2007) 'Subjects of Rejuvenation: Aging in Postfeminist Culture', in Y. Tasker and D. Negra (eds) Interrogating Postfeminism: Gender and the Politics of Popular Culture (Durham, NC: Duke University Press), pp. 277-310.

Williams, R. (2007) 'From Beyond Control to In Control: Investigating Drew Barrymore's Feminist Agency/Authorship', in S. Redmond and S. Holmes (eds) Stardom and Celebrity: A Reader (London: Sage), pp. 111-125.

Woodward, K. (1999) (ed.) 'Introduction', in Figuring Age: Women, Bodies, Generations (Indiana: Indiana University Press), pp. ix-xxix.

\section{Filmed}

Along Came Polly. Directed by John Hamburg. US, 2004.

The Break-Up. Directed by Peyton Reed. US, 2006.

Bruce Almighty. Directed by Tom Shadyac. US, 2003.

Friends. Created by David Crane and Marta Kauffman. US: NBC, 1994-2004.

He's Just Not That Into You. Directed by Ken Kwapis. US, 2009.

Horrible Bosses. Directed by Seth Gordon. US, 2011.

Horrible Bosses 2. Directed by Sean Anders. US, 2014.

Picture Perfect. Directed by Glenn Gordon Caron. US, 1997.

The Switch. Directed by Josh Gordon and Will Speck. US, 2010.

30 Rock. Created by Tina Fey. US: NBC, 2006-2013.

We're the Millers. Directed by Rawson Marshall Thurber. US, 2013. 